\title{
Innovation programs at the workplace for workers with an intellectual disability Australian organisations
}

\author{
Hannah Meacham
}

Department of Management, Monash University, Melbourne, Australia Jillian Cavanagh

Department of Management, Sport and Tourism, La Trobe Business School, College of Arts, Social Sciences and Commerce, La Trobe University, Melbourne, Australia Amie Shaw

Department of Employment Relations and Human Resources, School of Business, Griffith University, Gold Coast, Australia, and Timothy Bartram

Department of Management, Sport and Tourism, La Trobe Business School, College of Arts, Social Sciences and Commerce, La Trobe University, Melbourne, Australia

\begin{abstract}
Purpose - The purpose of this paper is to examine human resource management (HRM) innovation programs in the early stages of employment for workers with an intellectual disability (WWID).

Design/methodology/approach - The first case study was carried out at a large national courier company where a film innovation programme was used to enhance the socialisation process of WWID. The second case study was at a five-star hotel situated in a large city where a buddy system innovation programme was used in the induction and training process of WWID.

Findings - The overarching "life theme" created through these innovation programs was one of enhanced and creative opportunities for social inclusion. The participants displayed more confidence and independence in their ability and exhibited aspirations to advance and succeed in their roles.

Practical implications - The study argues that HR professionals need to be more proactive in finding innovative ways to engage WWID in the early stages of employment.

Originality/value - The qualitative study is underpinned by socialisation and career construction theory which provides the framework to discuss the ways in which socialisation and socially inclusive HRM practices enable participants and other WWID achieve success on their career paths. The key message of our research is that early vocational socialisation innovation programs can make a positive difference to the work experiences of WWID.
\end{abstract}

Keywords Qualitative, Human resource management, Socialization, Intellectual disability, Innovations, Career construction theory

Paper type Case study

(C) Hannah Meacham, Jillian Cavanagh, Amie Shaw and Timothy Bartram. Published by Emerald Publishing Limited. This article is published under the Creative Commons Attribution (CC BY 4.0) licence. Anyone may reproduce, distribute, translate and create derivative works of this article (for both commercial and non-commercial purposes), subject to full attribution to the original publication and authors. The full terms of this licence may be seen at http://creativecommons.org/licences/by/4.0/legalcode
Innovation

programs at the workplace for WWID

Received 24 August 2016 Revised 21 November 2016 Accepted 2 December 2016 
PR

46,7

1382

\section{Introduction}

This study is about workers with an intellectual disability (WWID) and the behaviours that create a positive "life theme" or a sense of purpose to encourage them through life, enabled through early innovation programs. Workplace innovation programs are introduced to workers in the initial stages of employment and aligned to an organisation's values and designed to generate new ideas and methods that better meet the needs of the organisation and individuals (Walsworth and Verma, 2007). The Australian Institute of Health and Welfare (2008) explains intellectual disability as difficulty learning, applying knowledge and making decisions, with individuals having difficulty adjusting to a change and interacting with unfamiliar people. People with intellectual disabilities are also likely to have a low intelligence quotient score (Alston $e t$ al., 2002; Price and Gerber, 2001). Hernandez et al. (2000) argued many employers espouse support for WWID but in reality are somewhat conflicted in their attitudes towards the employment of this cohort of workers. They report whilst some organisations have supported employment programs for training and development, they suggest there is an urgent need for more innovative programs to engage WWID and ensure positive outcomes. This is echoed in a recent paper by Ulrich (2016) on the future of human resource management (HRM), where he argues that for organisations to be effective, human resource (HR) needs to play a greater role in creating organisational values around the importance of respecting differences among organisational participants. Critical to achieving this is required for HRM to facilitate organisational participants to connect and care for one another through sharing lived experiences. Moreover, based on a comprehensive literature review, by Cavanagh et al. (2016) we found there is a dearth of research on the career issues and vocational workplace innovations that assist WWID to assimilate into the workplace. Therefore, our study contributes to conceptual and theoretical understandings of the potential career paths of WWID and the implications for HRM. It is important to better understand the career process of WWID to improve their workplace experiences. We conducted two case studies, underpinned by a series of interviews with managers across different organisational levels and focus groups/interviews with WWID to examine the impact of two very different HR vocational training innovation programs used by HR professionals. We applied Van Maanen and Schein's (1979) socialisation typology and Savickas' (2011) career construction theory to the HR vocational training innovation programme to illuminate WWID career adaptabilities and aspirations for the future. Career construction theory is about constructing meaning and an appropriate approach (Savickas et al., 2009; Savickas and Porfeli, 2012) that may well respond to the needs of WWID many of whom may be confused as they negotiate challenging work situations. Career construction is enabled through advice, coaching, role modelling and emotional support (Kulkarni, 2012). The rationale of this approach is to advance understandings about individuals' experiences at the workplace. In the first case study, we examine how WWID from a national courier company secured the opportunity to be involved in the film production sector, how these workers adapt to the environment of film-making and what it means for their future work experiences. This programme involves WWID featuring in a film where they provide their perspectives on work and their socialisation through work. In the second case study, we scrutinise a buddy system at a hotel site and how the system helps WWID adapt to work and influence their aspirations. A WWID is assigned a "buddy" who is generally a long-term employee and has the skills to train workers. We argue that HRM needs to take a greater interest in the career paths of WWID much earlier, and through innovative ways, which may enable these workers to build the coping skills necessary to navigate difficult changes in the open work environment (Nota et al., 2014; Savickas et al., 2009). Open employment is defined as doing a job which can be done by any person. A WWID will do the same job as their co-workers and are paid the same wages (Autism Spectrum Australia, 2016). Consequently, we argue that WWID should be better situated to 
make "real" life choices about their future work. This paper is guided by the following research question:

$R Q 1$. How can HR workplace innovation programs contribute to the socialisation and career construction of WWID?

Innovation

programs at

the workplace

for WWID

In this study, Van Maanen and Schein's (1979) socialisation typology and Savickas' (2012, 2009) career construction theory are applied to understanding the application of two HR workplace innovations to elucidate WWID career adaptabilities and aspirations for the future. Our paper contributes to HRM literature on WWID in two ways. First, there is an absence of research that examines the lived work experiences of WWID in open employment and contemporary strategies that $\mathrm{HR}$ managers can use to engage these workers (Kulkarni, 2012). The vast majority of literature on HRM and disability has focussed on physical accommodations and mental health awareness and management (Kaye et al, 2011). Moreover, there is limited research of WWID within the Australian context. Second, HRM research on WWID is generally focussed on securing their employment (Lengnick-Hall et al, 2008), rather than supporting them to develop their careers and enabling them to make life choices about their future work. Our paper is one of the first to examine of the process through which HRM workplace innovations are used to support and enable WWID. We go beyond traditional approaches to managing WWID to examine how HRM can be used to transform their lives.

The paper is structured in the following ways: first, a review of HR literature relative to management and workers with intellectual disabilities is carried out; second, socialisation theory and career construction theory will be outlined; third, the methodology of the study will be presented, followed by the results which identify the main factors influencing the vocational behaviours of people with intellectual disabilities. Finally, the implications of this research and avenues for further studies will be discussed.

\section{The role of HRM in supporting WWID}

There is evidence in the literature suggesting the employment of workers with disability is an issue for organisations because $\mathrm{HR}$ practitioners find it time consuming and challenging to employ and support WWID (Jones and Schmidt, 2004, Kennedy and Harris, 2003; Scheid, 2005). The average employment rates for workers with a disability are below 60 per cent across countries within the Organisation for Economic Co-operation and Development (2016). In Australia, only 1 million of the 2.2 million working aged adults with all types of disabilities are employed, representing 10 per cent of all Australian workers (Australian Bureau of Statistics, 2012). A general lack of management support makes it difficult for employers to employ workers with disabilities (Cunningham et al, 2004). Management practices impacting workplace issues are identified as the retention of WWD, training these workers and the performance of those who gain employment. Lengnick-Hall et al. (2008) examined employers' perceptions of individuals with disabilities and found that generally employers do not use a proactive approach in the recruitment of individuals with disabilities as they are concerned about their ability to perform. There may also be many practical reasons as to why employers are reticent to employ workers with disabilities. Kaye et al. (2011) contend that $\mathrm{HR}$ professionals mostly cite accommodation reasons for not hiring and retaining workers with disabilities. Graffam et al. (2002) research on 643 employers throughout Australia employing workers with a disability revealed certain issues; 75.2 per cent considered grooming and hygiene a problem; 74.6 per cent cited not working to a satisfactory standard as an issue; and 70.5 per cent considered the inability to undertake most assigned tasks critical to work.

Recent research has demonstrated that HR practitioners in partnership with all managers and employees within organisations can play an important role in eliminating discrimination of workers with disabilities (Nafukho et al, 2010). For example, Roessler et al. (2010) argued that HR professionals could potentially reduce discrimination against employees with 
PR

46,7

1384

disabilities by implementing early identification and prevention programs to provide reasonable accommodations, and flexible work schedules. The authors recommend the provision of disability awareness training to all employees to eliminate the discrimination against workers with disabilities. Scholars suggest HR management practices can be conducive of the socialisation and social inclusion of workers with disabilities (Messersmith et al., 2011, Abrams and Hogg, 2004, Graffam et al., 2002). However, management buy-in is essential to ensure an efficient disability procedure becomes part of a company's culture (Isernhagen, 2000) and evidence suggests that HR managers can achieve this through effective socialisation processes (Cooper-Thomas and Anderson, 2006).

\section{Socialisation}

Socialisation refers to the inclusive methods used in organisations to help newcomers adapt to joining a new organisation, to reduce uncertainty and learn appropriate attitudes and behaviours (Allen, 2006; Ge et al., 2010). According to Feldman (1976), successful socialisation is the transformation from an outsider to an integrated and effective insider and can include changes in or the development of new skills, knowledge, abilities, attitudes, values and relationships (Cooper-Thomas and Anderson, 2006).

Ge et al. (2010) suggested that socialisation is a combination of the learning process whereby individuals learn unspoken values and norms and also a process whereby the organisations can conform employees to follow and internalise organisational rules and values. Organisation socialisation is important for both employees and organisations as positive socialisation and inclusion reduced the negative impacts associated with the unmet expectations of newcomers which may lead to higher levels of turnover (Cooper-Thomas and Anderson, 2006); enables newcomers to meet performance expectations and feel as though they are making a valued contribution to the organisation (Van Maanen and Schein, 1979); and they also learn how to function in their organisation which requires learning the organisation's values and norms (Feldman, 1976; Cooper-Thomas and Anderson, 2006). Other positive outcomes associated with the socialisation of new employees' incudes higher levels of performance, increased job satisfaction, organisational commitment and retention (Korte and Li, 2015).

Organisational socialisation also aids managerial innovation programs to train new employees and instil organisational culture and values (Ge et al., 2010). Social interactions are primary foundations of socialisation, and these experiences are likely vary depending on cultural contexts (Morrison et al., 2004). However, Ge et al. (2010) contended that socialisation outcomes are often influenced by the interaction between organisational socialisation practices and the employees' pre-emptive behaviours. For instance, if an organisation does not embrace WWID then those employees with a disability may have a fear of not being accepted actually validated.

One of the most theoretically developed models of socialisation and the theoretical model used in this study is Van Maanen and Schein's (1979) typology of socialisation (Ashforth et al., 1998; Saks, 1997; Saks and Ashforth, 1996). Van Maanen and Schein's (1979) typology suggested that there are six types of socialisation practices: collective-individual, formalinformal, sequential-random, fixed-variable, serial-disjunctive and investiture-divestiture. Each form of socialisation tactic consists of a bipolar continuum (Ashforth et al., 1998). These practices are useful to identify areas of socialisation that challenge or prohibit full socialisation of WWID. This typology will be used in the study to investigate the types of socialisation practices used in the two innovation programs.

First, collective socialisation is where newcomers experience common learning experiences such as with a group or cohort, whereas with individual practices, each newcomer, such as a WWID, is exposed to learning experiences individually (Ashforth et al., 1998; Allen, 2006). Second, formal socialisation refers to segregating newcomers into clearly defined socialisation activities such as training classes while they learn their roles, whereas informal practices involve learning on the job during activities that may not be clearly defined socialisation activities (Ashforth et al., 
1998; Allen, 2006). WWID are more likely to struggle with training as opposed to their counterparts who may not have a disability. Third, sequential socialisation provides specific information to newcomers about the sequence of learning activities and experiences, whereas this sequence is unknown in a random process (Ashforth et al., 1998; Allen, 2006). Fourth, fixed socialisation provides information to newcomers about the timing associated with completing each socialisation stage or step, whereas this timing is unknown in a more variable process (Ashforth et al., 1998; Allen, 2006). Fifth, serial socialisation provides experienced organisational members as role models or mentors, whereas disjunctive practices do not provide experienced models (Allen, 2006; Ashforth et al., 1998). Finally, investiture socialisation provides newcomers positive social support from experienced organisational members, whereas divestiture practices provide more negative social feedback until newcomers adapt (Ashforth et al., 1998; Allen, 2006).

Authors such as Cooper-Thomas and Anderson (2006) emphasise the importance of having organisational insiders helping newcomers throughout the socialisation process. Organisational insiders such as peers and supervisors are seen to be a more useful source of knowledge and support than formal orientation programs (Cooper-Thomas and Anderson, 2006; Nelson and Quick, 1991; Louis et al., 1983). According to Morrison (2002), organisation insiders help newcomers to adjust by providing information and feedback, as well as being role models through providing social relationships and support. Kulkarni and Lengnick-Hall (2011) are among the few researchers who have investigated the influence of socialisation practices on workers with disabilities. They reported that the socialisation of workers with disabilities through supportive co-workers and supervisors was more important than formalised organisational practices. Organisational socialisation can enable or constrain career construction and development "through ties leading to instrumental assistance such as advice, coaching, protection, and advocacy and through emotional support, such as counseling, friendship, and role modelling" (Kulkarni, 2012). However, Kulkarni (2012) contended that there is a gap in the research concerning how the socialisation process of people with disabilities influences their career construction and advancement.

\section{Career construction theory}

Numerous career path theories have emerged to respond to the shifting world of work. For example, to support person-environment fit, vocational development emerged to explain the process through which workers could be matched to specific work profiles (Ballout, 2007). The subjective approach explores more on the regulation of workplace behaviours premised on interpreting what is happening now, not what happened in the past (Vinarski-Peretz et al., 2011). From a constructivist perspective an individual's work pathway is influenced by past and present experiences and future ambitions (Chen, 1998).

Savickas drew on the works of Super et al. (1988) and his earlier work on career development and Holland's (1997) personality typology, to develop career construction. Career construction theory is premised on personal and social constructivism and "asserts that individuals construct their careers by imposing meaning on their vocational behavior and occupational experiences" (Savickas, 2005) in order to be able to make decisions about their work. Individuals consider the outcomes of previous work experiences and base their future decisions on positive past experiences and avoiding those that were challenging. Savikas (2009) contended that an individual's involvement in real-life work experiences will help them to build the skills to adapt to future social change and influence their life experiences. When an individual has the opportunity explore him/herself in a certain situation, and learn more about their own abilities and skills, they are enabled to believe in themselves and how they might overcome future obstacles and challenges (Savickas and Porfeli, 2012; Savickas, 2011). Individuals need these abilities and skills to be able to pursue future aspirations.

Career construction theory can be applied to the vocational behaviours of individual workers through three dimensions of an individual: differences in personality traits; 
PR

46,7

1386

adaptability and coping strategies; and patterns across life themes (Savickas, 2005). This is useful to explain the career paths of WWID by taking into consideration their characteristics, coping approaches and life patterns/experiences that influence how they learn. Piaget (1975) postulated constructivism is premised on how learning happens for individuals and they ways in which they develop meaning based on their experiences. By examining Savickas' three perspectives through a film innovation programme and a buddy system we aim to gain understandings of what it means for workers with ID to be engaged in work.

This study applies theories on organisational socialisation and career construction to explore the world of a small cohort of people with intellectual disability and develop understandings of what it means for each of them to engage in the unique and creative environment of the film industry and a supportive buddy system. This paper aims to better understand how the strategies used in these HR vocational training innovation programs influence the socialisation and career construction of WWID and what it might mean for their future.

\section{Methodological approach}

We employed a qualitative case study methodology to investigate the two research sites and WWID. We acknowledge that the findings of our study will not be reported as generalisable to other organisations due to the relatively modest samples of two organisational sites. However, the two sites did provide the opportunity to compare and contrast two diverse organisations and the approaches they use to manage employees with an ID. Site 1 is a national courier company situated in a city and employs workers with various disabilities including WWID. Site 2 is a five-star hotel also situated in a city that employs mainly WWID. The managers at both sites had similar responsibilities in that they each managed a team of employees including WWID. They were involved in the recruitment, selection and training of workers within their teams. WWID undertook roles at Site 1 in general administration and office cleaning and Site 2 housekeeping and laundry duties. The sample of workers with intellectual disability comprised of people with cognitive and learning disabilities, down syndrome and autism. To respond to the research question our approach was to conduct interviews, a focus group and observations. Bryman (2004) recommended the case study approach, with triangulation of several sources of data, as the most reliable approach to gain valuable insights into the phenomenon of workers, such as those with intellectual disability.

\section{Methods}

As both researchers and observers, we were able to initiate the analysis of the data from the two case study sites commencing with our first visit to each organisation. At this point, we were in a position to identify initial research themes in the data. During these phases, it was imperative that the researchers gave consideration to accuracy in what was observed (Lofland, 2006) whilst remaining sensitive to the relationship with the participants (Seidman, 1991). Savickas (2011, 2013) developed an interview script that he suggests can be used through interviews or group sessions with participants. Interviews with the participant organisations and the film company explored the opportunities afforded WWID to develop a film on inclusion. A focus group session was held with the five WWID at research Site 1 and separate interviews were carried out with six WWID at research Site 2. This approach was the most appropriate, as it was the least intrusive method of establishing what the participant workers knew about their working environment that helped or perhaps impeded their involvement in the work innovation programme project (Lofland, 2006) with the film company.

\section{Data collection and analysis}

Once data were collected, the researchers searched for emergent concepts and conceptualisation of contributions to the field that might also be of benefit to the many other workers with 
intellectual and perhaps other disabilities. The analysis of this study was activated at the research settings and determined emergent understandings arising from the data relevant to the research setting (Glaser and Strauss, 1967; Glaser, 1992, 1998). A foundational approach to the analysis of raw data was integrated with a second stage process to conceptualise information into categories (Glaser, 1998). Constant comparative methods fostered the discovery of relationships, categories and characteristics (Lecompte and Goetz, 1984). This revealed participants personal traits, successes and coping strategies (Anzul et al., 2001).

The following two sections present the collection and analyses of data from the two research sites. We begin with Case Study 1.

\section{Case study Site 1}

Within the national courier company five employees, each with an intellectual disability, won a competition to be involved in a film innovation programme to promote socialisation and inclusion across the workplace. Through interviews, with a representative of the company and the owner of the film-making organisation, we aim to develop understandings about the background and purpose of the HR vocational training innovation programme. A focus group of five workers, with intellectual disabilities, provided the setting to examine how workers became involved in the film and the patterns of their vocational behaviours.

\section{Interviews}

We conducted two interviews at research site 1: first, we met with the owner of the film company, followed by the client company who contracted the film company. Our first question directed at the owner of the film company was to explore the purpose of the film innovation programme:

The film company is a start-up, voluntarily run, not-for-profit organisation. Through a partnership with a local Community College we hold film-making workshops and make films with our participants with an intellectual disability. On every film project people living with a disability fulfil cast and crew roles in a supported environment with mentorship. This creates an inclusive environment and an opportunity for our students to make a professional short film with firsthand experience of what it's like to be on a professional film set. It also means that industry professional can enjoy the opportunity to be a mentor, creating true inclusion in the film industry (Owner, Film Company).

Moreover, we were keen to gain information about why and how the film makers decided to use employees with intellectual disability in the film production:

The need for more inclusion and opportunities in an industry that is notoriously difficult for anyone to participate in. The film industry can be cut throat and discriminatory if you are not in your 20's and a supermodel, so helping people gain experience [...] is very rewarding. The community college approached us to run workshops for students [....] the idea just grew into a short film.

In our second interview, we were interested to establish the rationale behind why a large company had employed a film company to develop a HR vocational training innovation programme by way of a film to promote inclusion in the workplace. We asked the HR manager to explain the rationale behind the project:

The organisation set an accessibility action plan, giving [...] employment opportunities for employees, customers and the community. For the majority of the population, inclusion is not given a second thought $[\ldots]$ however, for people who are a bit different $[. .$.$] it is very different$ $[\ldots]$ the organisation rolled out disability awareness training $[\ldots]$ the organisation wanted to create an innovative way for building inclusion and conveying disability awareness to their employees. 
PR

46,7

1388

\section{Focus group}

A focus group of the five workers was held at the company. The focus group was held for one hour and was attended by a counsellor who was ready to moderate the meeting if any issues arose. The researchers first explored how the workers became involved in the film project. One of the WWID was quick to provide the answer and explained that each of the workers "had to put in a story about workers with a disability" (David, WWID). The five winners were chosen based on their personal stories, work histories and personal traits.

\section{Personality traits of WWID}

We were looking for distinct characteristics of each individual in the study.

The researcher asked the focus group members what motivated each of them to be involved in the project:

CE4: For me it was just to share my story and why I enjoy working here $[\ldots]$.

CE1: I agree, it's about sharing the experience that we have. Not everyone works with someone who has a disability so for me I wanted it to be a bit of an eye opener [for other co-workers].

CE3: It was important to start conversations about workers with disabilities and inclusion [...] one of the biggest barriers to inclusion is most people have not worked with a worker with a disability $[\ldots]$ we are a very insular society.

CE2: Didn't want the sympathy card to be played [...] we want [other workers] to want to be inclusive.

CE5: $[\ldots]$ Colleagues from the CEO to the tea lady are talking about it [the film].

Through the participants' responses and comments we were able to identify some of their personality traits. Each of the participants shared the same characteristic of "openness" when they aspire for other workers to know who they are and what their stories are about. $\mathrm{CE} 1$ indicated he sought to "share" his experiences and raise awareness. CE3 supported this view and was keen to start conversations, which was evidenced by CE5's comments on the fact everyone in the organisation is "talking about it [the film]". Identifying personality traits can be useful for the HR team to tailor workplace integration programs by ascertaining similar behaviours and interests among WWID and colleagues.

\section{Adapting to the work innovation}

The HR workplace innovation was the topic of the second question. The participants were asked how they adapted to working and being involved in the film project:

CE5: $[\ldots]$ we had a little committee $[\ldots]$. all workers $[\ldots]$ knew about the project.

CE3: Being an extra was great fun [...]. I haven't laughed so much [...] there was a lot of work but they made it fun $[\ldots]$.

CE1: I consulted on the story [...]. They [film crew and producer] made me feel so welcome [...] almost the star of the show [...] felt like my own movie.

It was evident the participants enjoyed the entire experience of being involved in the making of the film. The participants were encouraged to share what happened for them after the release of the film:

CE1: We had a huge launch day with a real premier [...] we all got put up in hotels, dressed up and walked the red carpet $[\ldots]$.

CE3: We were able to watch the film and there were even a few copies to borrow and take home to our family. 
CE4: There was so much promotion you couldn't get away from it [...].

Innovation

There was much pride in the voices of the participants. The participants were also asked about the reaction of other workers after they had viewed the film:

CE3: One lady came up to me crying, saying the film had affected her so much [...].

programs at

the workplace

for WWID

CE2: I think it has helped a lot for the culture of the business [...] people are making the effort to speak $[\ldots]$.

It was evident work colleagues were impacted by the film because WWID indicated they were more socially accepted by other work colleagues. Where once the WWID might be ignored, they now enjoyed a social acceptance. Following the release of the film the general population of workers treated WWID with dignity indicating socialisation process had been enhanced. This again shows the importance of socialisation programs that could be implemented by HR policies such as the two innovations seen in this study.

\section{Work/life themes}

The participants were visibly excited when they talked about the film. The researcher explored how the participants felt post the release of the film and a new work/life theme appeared to emerge from making the film:

CE3: I definitely feel more included [...] people are more aware of us and what we need $[\ldots]$ everyone can see an element of themselves [...] whether it be the worker with a disability or colleagues.

CE2: There's a sense of camaraderie now [...] bringing in the awareness in an easy format such as a film.

CE5: $[\ldots]$ it has changed things $[\ldots]$ awareness is the biggest thing.

CE1: I think everyone is more aware of us [...]. I am almost a celebrity [...] people "Oh $[\ldots]$ you're the film guy" $[\ldots]$ it's good to see they've watched it [...] it's fun to watch $[\ldots]$ had some very funny moments.

If work colleagues had previously viewed themselves as very different from other workers with a disability it appears they may have reason to re-think.

\section{Case study Site 2}

At research site 2 we conducted interviews with the HR manager and six WWID. We met with the HR manager and asked him/her about their HR vocational training innovation programme. The HR manager explained "We have workers with intellectual disability [...] the Australian public is very generous, [...] there are lots of positive comments from our guests, they appreciate the work put in by workers with disabilities". The manager went on to explain the "buddy system" where each WWID is assigned a mentor for two weeks following basic training in any section they may be employed.

\section{Personality traits of WWID}

Prior to the innovation programme some of the workers indicated they were very nervous about being around guests. In their talk they told us they were not very confident before they started work:

WD2: I thought guests would shout at me or stare because I am different but they are nice and guests who come back remember me and say hello, I have my regulars.

WD3: This worker's buddy "helped me learn what I had to so after my training [...] my partner [buddy] helps me remember what I have to do. 
PR

46,7

The implementation of a buddy system not only ensures WWID are trained effectively but also gives them regular and purposeful interaction with colleagues. This not only provides opportunities for socialisation that may not have been possible outside the workplace, but also develops their personal interaction skills which may lead to career progression.

\section{Adapting to the work innovation programme}

WD4: My buddy shows me what to do in the laundry and how to be safe.

WD2: Learned the skills to "stack the bags on the trolley, how to talk to guests, how to tag the bags for storage and he would have lunch with me.

WD3: I sometimes feel stupid [...] but they say always ask, don't struggle.

The "buddy system" programme is designed to help workers for the first two weeks of employment. However, the system is flexible if workers need additional help. There are additional benefits for the WWID through the relationships they build at work:

WD1: I needed longer with my buddy [...] I was given the option.

WD5: I still have my buddy [...] we work on the same floor and she helps me do my rooms.

WD6: I'm so much more confident now [...] having normal friends makes me feel normal.

It is essential that HR practices are flexible to allow for additional support if needed by the WWID. If HR practices are too rigid and formulaic, WWID may not receive the support they require and consequently may lose confidence and begin to underperform.

\section{Work/life themes}

The participants were very happy to articulate how the film had influenced their aspirations for the future. The positive experiences of the WWID tell the story of how the workers develop future ambitions:

WD1: I would like to be a supervisor [...] I have done a few training modules [...].

WD2: I would like to be a buddy so I can teach the new porters what to do. I want to pass on all my knowledge I have got from the past 8 years.

WD3: I feel normal, I can talk to different people and not just parents [...] we all have lunch together $[\ldots]$ when the managers organise something for us.

WD4: I like money to spend at motor-cross [...]I like working because I'm doing things and not just at home.

WD2: You can be rich and unhappy [...] but I'm happy so I'm more successful. I moved out of my parents' house $[\ldots]$ it's a big thing.

WD4: I do the job they tell me to do so I think I'm successful.

Through implementing a workplace innovation, such as a "buddy" system and the film, HR practices may enable WWID to perform to their full potential, expand their career aspirations and open up workplace opportunities for the WWID.

\section{Discussion and conclusion}

In this paper, we have explored workplace innovations as part of a broader HRM approach to supporting WWID. A major finding of this study is that workplace innovations go beyond traditional disability awareness programs to create a workplace climate of support for WWID. Moreover, socialisation practices play an important role in the career construction and perceived success by WWID. We also found that the innovation programs 
presented in our paper help WWID feel inspired, give them a sense of purpose, and allow them to develop future career aspirations. WWID reported that their acceptance and integration at the workplace increased beyond their initial expectations as a result of the implementation of workplace innovations. We discuss these key points in turn with an emphasis on theory building in HRM, implications for management practitioners and future research on WWID.

First, the feeling of inclusion through HRM socialisation practices appeared to help increase the confidence and independence of WWID to develop their own career aspirations and construct their own careers, as well as contribute to their own personal development and the success in their current role. Our study has demonstrated that by articulating the processes by which WWID apply their personal characteristics to work experiences, and being cognisant of the ways in which they adapt to work environments, helps each of them create a "life theme" of positive adaptability and stimulates their aspirations for the future. This study has demonstrated how two very different $H R$ vocational training programs, both illustrating various socialisation practices, have a positive impact on the career construction and overall confidence and interdependence of WWID. Underpinning the success of these training innovations were well-articulated programs that involved supervisors, WWID and their colleagues in the development, delivery and evaluation phases. A high level of staff participation in the development of workplace innovations is a critical component to its successful "buy-in" from staff and implementation (Kalmi and Kauhanen, 2008; Brown and Cregan, 2008). The development of HR innovations that unite staff, break down misconceptions and incorrectly held beliefs is crucial to enhancing the socialisation and ultimately the inclusion of people with disability at the workplace (Cavanagh et al., 2016; Roessler et al., 2010; Cavanagh et al., 2013).

Second, the rationale behind the film innovation programme was about disability awareness training and finding an innovative way to build inclusion and create disability awareness for all employees. Rossler et al. (2010) emphasised the importance of having disability awareness training for all employees to eliminate the discrimination against workers with disabilities. Elements of fixed and sequential socialisation were evident as the workers have specific information and knowledge about the innovation programme and the desired learning experiences and outcomes. Informal socialisation was seen as workers were about to engage in the experience first-hand "helping people gain experience" and submerge themselves in the actual experiences, rather than being governed by more formal mechanisms. According to Piaget (1975) and Savikas (2009), it is the real-life work experiences that help individuals to build their skills and abilities, and develop the confidence to start thinking and working towards their future career aspirations. In fact, HR innovations establish frameworks through which managers, WWID and their colleagues can develop meaningful and supportive workplace relationships that promote the social inclusion of WWID. Serial socialisation was evident in the film innovation programme through the use of the film crew as role models and mentors to WWID. Both informal and serial socialisation practices led to increased levels of "true inclusion" among WWID. In the case of the film innovation, it is clear that it was informal processes around the interaction of all participants enabled WWID to feel included and valued. Investiture socialisation was apparent through the use of experienced members as mentors, such as the producer providing support and consultation to workers. Informal, serial and investiture socialisation results in WWID feeling happy, "I haven't laughed so much [...] made it fun" and "made me feel so welcome [...] the star of the show". These findings are important for HR practitioners and managers because they demonstrate the value to WWID and their colleagues of positive interaction and participation in co-producing innovation at the workplace in which all workers' input irrespective of disability is sought and valued. The concept of co-producing innovation in the employment of WWID to our knowledge has not been examined in the 
PR

46,7

1392

HRM literature but represents a significant opportunity for HRM to support WWID inclusion and career opportunities. Voorberg et al. (2015) offered insight into the potential for social innovation to address social challenges through changing relationships, positions and rules between workplace participants. Our findings demonstrate the potential for organisations to strengthen the social inclusion and career trajectories of WWID through co-production of workplace innovation.

Third, a combination of formal and informal socialisation practices were used with the buddy system innovation programme, as formal training is initially provided and then workers get the opportunity to work with their buddy, ask questions as they go and learn for informally on the job. Sequential socialisation was demonstrated through the buddy systems, with buddies acting in the role of mentor and guiding WWID through work tasks and aiding the socialisation and inclusion process. Variable socialisation was evident through WWID having the flexibility to connect with their buddy for longer if needed. The importance of WWID feeling included in their work environment was also emphasised in the second case study. The feeling of inclusion seems to be manifested in workers' confidence and self-esteem in being able to do their jobs. These findings have important implications for HR managers. We would encourage the implementation of socialisation programs that commence immediately upon the employment of WWID. Socialisation of employees is an important starting point in building a cohesive and committed workforce (Ulrich, 2016). Through HR managers working in partnership with line management and all cohorts of workers our findings show that informal and serial socialisation practices seem to increase reported levels of inclusion among WWID.

One of the main outcomes of the buddy innovation programs was that WWID felt inspired, achieved a sense of purpose and developed future aspirations about their work and career paths. WWID talked about different career aspirations and how it was important for them to be happy and successful, "I'm happy so I'm more successful". Our findings correspond with Kulkarni (2012) and reinforce the important role that socialisation practices play in the career construction of WWID. More specifically, this study found that socialisation practices that involve role models and mentors (serial socialisation) including those that are senior to the organisation (investiture socialisation) were flexible (variable socialisation) and occurred on the job and involved learning from real-time experiences related to real-life experiences (informal socialisation) seem to enable WWID to feel more confident to perform their job and experience a higher desire to develop and pursue future career aspirations. This is an important finding as the vast majority of HRM literature on workers with disability is focussed on the employment and retention of this cohort of workers, rather than strengthening their abilities and confidence to perform and build successful careers (Cavanagh et al., 2016). Our results give some insight into the process through which HRM can begin to move from a traditional anti-discrimination and fairness approach to disability employment, to one that encompasses a learning and integration approach that values the unique gifts, talents and abilities of WWID (Thomas and Ely, 1996). We argue that this change in approach must be underpinned by a well-articulated mission and value statement, egalitarian organisational structures that encourage openness and the stimulation of personal development through workplace opportunities for WWID (Thomas and Ely, 1996).

Our findings raise a number of practical implications for HR managers. We have documented the process through which two examples of workplace innovations have been used by managers to support orientation and the socialisation and inclusion of WWID. Workplace innovations to provide benefit to WWID, their colleagues and organisation more broadly do not necessarily have to be complicated or expensive. We would encourage HR managers to first develop workplace innovations tailored to their own organisational, industry and customer needs especially during the early stages of the employment of 
WWID as a way to promote inclusion and valuing difference at the workplace. We share the view that this not only makes sense ethically and morally, but also economically, as all workers in the organisation, irrespective of difference can value and support one another (Ulrich, 2016; Kulkarni, 2012; Lengnick-Hall et al., 2008). The findings present a challenge to HR practitioners to explore the outcomes of early interventions beyond orientation. HR needs to consider positive associations between early intervention programs and performance and respond with appropriate policy and practice. Other consequences can be linked to tenure. HR may find that early intervention programs set the scene to secure longtime tenure. Also, through proactive approaches, HR can help create a positive culture of inclusion and to some degree meet their corporate social responsibilities. Although legislation outlawing the discrimination of people with disability in employment is vital (Hanley and O'Rourke, 2015), we argue that HR has an important role in developing and promoting the business case for the employment for people with disabilities. One of the most powerful findings in our study is the potential of HRM innovations that are co-produced with all organisational participants to impact not only the social inclusion of WWID, but also the way in which they perform and contribute to the business in a positive way.

Despite our valuable findings, this paper is not without its limitations. The results are based on two qualitative case studies and therefore limit their generalisability to other organisations. Moreover, given our methodological approach it is difficult to infer causality - that is we do not know if the workplace innovations were associated with improvements in the well-being and performance of WWID. Consequently, we would encourage future research using more robust quantitative approaches. This would necessitate a quasi-experimental research design that measures pre- and post-test well-being and performance scores following the introduction of workplace innovations/interventions. We would also recommend future research explore the impact of HR disability innovations in other organisational and industry contexts.

In conclusion, our findings support the value of HR professionals, managers and workers' supporting, through HR innovations, the socialisation and inclusion of WWID. Organisations need to value the abilities, gifts and talents of WWID and harness them through workplace innovations that support the integration and learning of all workers. This must be underpinned by the participation of WWID, their colleagues and managers across the organisation to create workplaces that value difference and harness it to build both individual and organisational success. It is through valuing difference and backing it up through practical workplace innovations that we might see more WWID not only engaged in employment, but also building successful careers and more importantly success lives.

\section{References}

Abrams, D. and Hogg, M.A. (2004), "Collective identity: group membership and self-conception", in Brewer, M.B. and Hewstone, M. (Eds), Perspectives on Social Psychology, Self and Social Identity, Blackwell Publishing, Malden, pp. 147-181.

Allen, D.G. (2006), "Do organizational socialization tactics influence newcomer embeddedness and turnover?”, Journal of Management, Vol. 32 No. 2, pp. 237-256.

Alston, R., Bell, T. and Hampton, J. (2002), "Learning disability and career entry into the sciences: a critical analysis of attitudinal factors", Journal of Career Development, Vol. 28, pp. 263-275.

Anzul, M., Evans, J.F., King, R. and Tellier-Robinson, D. (2001), "Moving beyond a deficit perspective with qualitative research methods", Exceptional Children, Vol. 67, pp. 235-249.

Ashforth, B.E., Saks, A.M. and Lee, R.T. (1998), "Socialization and newcomer adjustment: the role of organizational context”, Human Relations, Vol. 51 No. 7, pp. 897-913.

Australian Bureau of Statistics (2012), "Disability, Ageing and Carers", Australian Bureau of Statistics, ACT, Canberra. 
PR

46,7

1394

Australian Institute of Health and Welfare (2008), Disability in Australia: Intellectual Disability, AIHW, Canberra.

Autism Spectrum Australia (2016), “Open employment” available at: www.autismspectrum.org.au/ (accessed 16 November 2016).

Ballout, H.I. (2007), "Career success: the effects of human capital, person-environment fit and organizational support”, Journal of Managerial Psychology, Vol. 22 No. 8, pp. 741-765.

Brown, M. and Cregan, C. (2008), "Organizational change cynicism: the role of employee involvement", Human Resource Management, Vol. 47 No. 4, pp. 667-686.

Bryman, A. (2004), "Qualitative research on leadership: a critical but appreciative review", The Leadership Quarterly, Vol. 15 No. 6, pp. 729-769.

Cavanagh, J., Mcneil, N. and Bartram, T. (2013), "The Australian men's sheds movement: human resource management in a voluntary organisation", Asia Pacific Journal of Human Resources, Vol. 51 No. 3, pp. 292-306.

Cavanagh, J., Bartram, T., Meacham, H., Oakman, J., Bigby, C. and Fossey, E. (2016), "Supporting workers with disabilities: a scoping review of the role of human resource management in contemporary organisations", Asia Pacific Journal of Human Resources, Vol. 55 No. 1, pp. 6-43.

Chen, C.P. (1998), "Understanding career development: a convergence of perspectives", Journal of Vocational Education and Training, Vol. 50 No. 3, pp. 437-461.

Cooper-Thomas, H.D. and Anderson, N. (2006), "Organizational socialization: a new theoretical model and recommendations for future research and HRM practices in organizations", Journal of Managerial Psychology, Vol. 21 No. 3, pp. 492-516.

Cunningham, I., James, P. and Dibben, P. (2004), "Bridging the gap between rhetoric and reality: line managers and the protection of job security for ill workers in the modern workplace", British Journal of Management, Vol. 15 No. 3, pp. 273-290.

Feldman, D.C. (1976), “A practical program for employee socialization”, Organizational Dynamics, Vol. 5 No. 2, pp. 64-80.

Ge, J., Su, X. and Zhou, Y. (2010), "Organizational socialization, organizational identification and organizational citizenship behavior: an empirical research of Chinese high-tech manufacturing enterprises", Nankai Business Review International, Vol. 1 No. 2, pp. 166-179.

Glaser, B.G. (1992), Emergence vs. Forcing: Basics of Grounded Theory Analysis, Sociology Press, Mill Valley, CA, pp. 129-148.

Glaser, B.G. (1998), Doing Grounded Theory: Issues and Discussions, Sociology Press, Mill Valley, CA, pp. 254-268.

Glaser, B.G. and Strauss, A. (1967), The Discovery of Grounded Theory: Strategies for Qualitative Research, Aldine, Chicago, IL.

Graffam, J., Shinkfield, A., Smith, K. and Polzin, U. (2002), "Factors that influence employer decisions in hiring and retaining an employee with a disability", Journal of Vocational Rehabilitation, Vol. 17 No. 3, pp. 175-181.

Hanley, G.M. and O'Rourke, A. (2015), "The race without a finishing line: legislative means for confronting bullying in the Australian workplace", Asia Pacific Journal of Human Resources, Vol. 54 No. 3, pp. 352-368.

Hernandez, B., Keys, C. and Balcazar, F. (2000), "Employer attitudes toward workers with disabilities and their ADA employment rights: a literature review", Journal of Rehabilitation, Vol. 66 No. 4, pp. 4-16.

Holland, J. (1997), Making Vocational Choices: A Theory of Vocational Personalities and Work Environments, Prentice-Hall, Englewood Cliffs, NJ.

Isernhagen, D.D. (2000), "A model system: integrated work injury prevention and disability management”, Work, Vol. 15 No. 2, pp. 87-94.

Jones, P. and Schmidt, R. (2004), "Retail employment and disability", International Journal of Retail \& Distribution Management, Vol. 32 No. 9, pp. 426-429.

Kalmi, P. and Kauhanen, A. (2008), "Workplace innovations and employee outcomes: evidence from Finland", Industrial Relations: A Journal of Economy and Society, Vol. 47 No. 3, pp. 430-459. 
Kaye, H.S., Jans, L.H. and Jones, E.C. (2011), "Why don't employers hire and retain workers with disabilities?”, Journal of Occupational Rehabilitation, Vol. 21 No. 4, pp. 526-536.

Kennedy, R.B. and Harris, N.K. (2003), "Employing people with severe disabilities: the challenge remains", Journal of Employment Counseling, Vol. 40 No. 2, pp. 80-86.

Korte, R. and Li, J. (2015), "Exploring the organizational socialization of engineers in Taiwan”, Journal of Chinese Human Resource Management, Vol. 6 No. 1, pp. 33-51.

Kulkarni, M. (2012), "Social networks and career advancement of people with disabilities", Human Resource Development Review, Vol. 11 No. 2, pp. 138-155.

Kulkarni, M. and Lengnick-Hall, M.L. (2011), "Socialization of people with disabilities in the workplace", Human Resource Management, Vol. 50 No. 4, pp. 521-540.

Lecompte, M. and Goetz, J. (1984), Ethnography and Qualitative Design in Educational Research, Academic Press, Orlando, FL.

Lengnick-Hall, M., Gaunt, P.M. and Kulkarni, M. (2008), "Overlooked and underutilised: people with disabilities are an untapped human resource", Human Resource Management Review, Vol. 47 No. 2, pp. 255-273.

Lofland, J. (2006), Analyzing Social Settings: A Guide to Qualitative Observation and Analysis, Thomson Learning, Bellmont, $\mathrm{CA}$ and Wadsworth, $\mathrm{OH}$.

Louis, M.R., Posner, B.Z. and Powell, G.N. (1983), "The availability and helpfulness of socialization practices", Personnel Psychology, Vol. 36 No. 4, pp. 857-866.

Messersmith, J.G., Patel, P.C., Lepak, D.P. and Gould-Williams, J.S. (2011), "Unlocking the black box: exploring the link between high-performance work systems and performance", Journal of Applied Psychology, Vol. 96 No. 6, pp. 1105-1118.

Morrison, E.W. (2002), "Newcomers' relationships: the role of social network ties during socialization", Academy of Management Journal, Vol. 45 No. 6, pp. 1149-1160.

Morrison, E.W., Chen, Y. and Salgado, S.R. (2004), "Cultural differences in newcomer feedback seeking: a comparison of the United States and Hong Kong", Applied Psychology: An International Review, Vol. 53 No. 1, pp. 1-22.

Nafukho, F.M., Roessler, R.T. and Kacirek, K. (2010), "Disability as a diversity factor: implications for human resource practices", Advances in Developing Human Resources, Vol. 12 No. 4, pp. 395-406.

Nelson, D.L. and Quick, J.C. (1991), "Social support and newcomer adjustment in organizations: attachment theory at work?", Journal of Organizational Behavior, Vol. 12 No. 6, pp. 543-554.

Nota, L., Santilli, S., Ginevra, M.C. and Soresi, S. (2014), "Employer attitudes towards the work inclusion of people with disability", Journal of Applied Research in Intellectual Disabilities, Vol. 27 No. 6, pp. 511-520.

Organisation for Economic Co-operation and Development (2016), "Disability", available: www.oecd.org/ (accessed 13 July 2016).

Piaget, J. (1975), The Development of Thought: Equilibration of Cognitive Structures, Viking Penguin, New York, NY.

Price, L. and Gerber, P. (2001), "At second glance: employers and employees with learning disabilities in the Americans with disabilities Act era", Journal of Learning Disabilities, Vol. 34 Nos 202-210, p. 248.

Roessler, R., Hurley, J. and Mcmahon, B. (2010), “A comparison of allegations and resolutions involving issues of discharge versus constructive discharge: implications for diversity management", Advances in Developing Human Resources, Vol. 12 No. 4, pp. 407-428.

Saks, A.M. (1997), "Organizational socialization: making sense of the past and present as a prologue for the future", Journal of Vocational Behavior, Vol. 51 No. 2, pp. 234-279.

Saks, A.M. and Ashforth, B.E. (1996), "Proactive socialization and behavioral self-management", Journal of Vocational Behavior, Vol. 48 No. 3, pp. 301-323.

Savickas, M.L. (2005), "The theory and practice of career construction”, in Lent, R.W. and Brown, S.D. (Eds), Career Development and Counselling: Putting Theory and Research to Work, John Wiley \& Sons, Hoboken, NJ, pp. 42-67. 
PR

46,7
Savickas, M.L. (2011), "Constructing careers: actor, agent, and author", Journal of Employment Counseling, Vol. 48 No. 4, pp. 179-181.

Savickas, M.L. and Porfeli, E.J. (2012), "Career-adapt-abilities scale: construction reliability and measurement equivalence across 13 countries", Journal of Vocational Behavior, Vol. 80 No. 3, pp. 661-673.

Savickas, M.L., Nota, L., Rossier, J., Dauwalder, J.P., Duarte, M.E., Guichard, J., Soresi, S., Van Esbroeck, R. and Van Vianen, A.E.M. (2009), "Life designing: a paradigm for career construction in the 21st century", Journal of Vocational Behavior, Vol. 75 No. 3, pp. 239-250.

Scheid, T.L. (2005), "Stigma as a barrier to employment: mental disability and the Americans with disabilities act", International Journal of Law and Psychiatry, Vol. 28 No. 6, pp. 670-690.

Seidman, I.E. (1991), Interviewing as Qualitative Research, Teachers College Press, New York, NY.

Super, D.E., Thompson, A.S. and Lindeman, R.H. (1988), Adult Career Concerns Inventory: Manual for Research and Exploratory Use in Counselling, Consulting Psychologists Press, Palo Alto, CA.

Thomas, D.A. and Ely, R.J. (1996), "Making differences matter", Harvard Business Review, Vol. 74 No. 5, pp. 79-90.

Ulrich, D. (2016), "HR at a crossroads", Asia Pacific Journal of Human Resources, Vol. 54 No. 2, pp. 148-164.

Van Maanen, J. and Schein, E.H. (1979), “Towards a theory of organizational socialization”, in Staw, B.M. (Ed.), Research in Organizational Behavior, JAI, Greenwich, CT, pp. 209-264.

Vinarski-Peretz, H., Binyamin, G. and Carmeli, A. (2011), "Subjective relational experiences and employee innovative behaviors in the workplace", Journal of Vocational Behavior, Vol. 78 No. 2, pp. 290-304.

Voorberg, W.H., Bekkers, V.J. and Tummers, L.G. (2015), "A systematic review of co-creation and co-production: Embarking on the social innovation journey”, Public Management Review, Vol. 17 No. 9, pp. 1333-1357.

Walsworth, S. and Verma, A. (2007), "Globalization, human resource practices and innovation: recent evidence from the Canadian workplace and employee survey", Industrial Relations: A Journal of Economy and Society, Vol. 46 No. 2, pp. 222-240.

\section{Further reading}

Bryman, A. (2015), Social Research Methods, Oxford University Press, Oxford.

\section{About the authors}

Dr Hannah Meacham is a Lecturer in Human Resource Management at Monash University. Her research interests include: human resource management, employer support and the employment of workers with disabilities; strategic and global human resource management. Dr Hannah Meacham is the corresponding author and can be contacted at: hannah.meacham@monash.edu

Dr Jillian Cavanagh is the La Trobe University Business School Graduate Research Coordinator. Her research interests include: human resource management, employer support and the employment of workers with disabilities; men's groups and sheds, community development and engagement; Aboriginal and Torres Strait Islander men's health and participation in men's sheds.

Dr Amie Shaw is a Lecturer in the School of Business, Griffith University. Her research interests include: human resource management (development, retention and leadership practices), graduate readiness, employability and professional identity, disability workers and men's health and community organisations (men's sheds).

Timothy Bartram is a Professor of Human Resource Management, La Trobe University. His research interests include: human resource management, employer support and the employment of workers with disabilities; high performance work teams; human resource management (HRM) in health care and Indigenous men's sheds.

For instructions on how to order reprints of this article, please visit our website:

www.emeraldgrouppublishing.com/licensing/reprints.htm

Or contact us for further details: permissions@emeraldinsight.com 